\title{
Article \\ Comparison of the Experimental Measurement Methods for Building Envelope Thermal Transmittance
}

\author{
Xinrui Lu ${ }^{1, *(1)}$ and Ali M. Memari ${ }^{1,2}$ \\ 1 Department of Civil and Environmental Engineering, Penn State University, University Park, PA 16802, USA; \\ amm7@psu.edu \\ 2 Department of Architectural Engineering, Penn State University, University Park, PA 16802, USA \\ * Correspondence: luxinruipsu@gmail.com
}

Citation: Lu, X.; Memari, A.M. Comparison of the Experimental Measurement Methods for Building Envelope Thermal Transmittance. Buildings 2022, 12, 282. https:// doi.org/10.3390/buildings12030282

Academic Editor: Fabrizio Ascione

Received: 1 February 2022

Accepted: 23 February 2022

Published: 1 March 2022

Publisher's Note: MDPI stays neutral with regard to jurisdictional claims in published maps and institutional affiliations.

Copyright: (c) 2022 by the authors. Licensee MDPI, Basel, Switzerland. This article is an open access article distributed under the terms and conditions of the Creative Commons Attribution (CC BY) license (https:// creativecommons.org/licenses/by/ $4.0 /)$.

\begin{abstract}
Building energy consumption and ways to reduce it have drawn increasing attention in recent decades. Thermal transmittance is not only a code-enforced parameter during the design and retrofit phase of building assemblies, but also strongly related to the accuracy of whole-building energy modeling. There are several existing methods to measure the building envelope thermal transmittance, and with the development of new techniques, more practical and precise measurement methods have been explored. The study discussed here focused on comparing methods to measure the building envelope thermal transmittance, both in laboratory and for in-situ measurement. Typical research studies related to the Hot Box Test Method, the Heat Flow Meter Method and the Infrared Thermography Method are described and compared. This paper provides a state-of-the-art review of the up-to-date measurement methods for building envelope thermal transmittance and provides alternatives for engineers, architects and researchers to practically measure the building envelope thermal transmittance.
\end{abstract}

Keywords: building envelope; energy performance; thermal transmittance; dynamic modeling; Infrared Thermography

\section{Introduction}

Building energy use accounts for a large percentage of energy consumption in the U.S., up to $40 \%$ for both residential and commercial buildings [1]. It is recognized that one of the most significant factors in building energy consumption is the energy loss through building envelope (BE) systems. As the thermal transmittance (U-factor) of building envelope systems has direct effect on building energy performance, accurate U-factor of the BE system would need to be determined for realistic energy modeling of both new construction and retrofit projects.

The U-factor (whose reciprocal also known as the "overall R-value"), together with some other variables, can cause a $75 \%$ variance in building energy rating [2]. Usually, during the design phase of new construction, the U-factor is estimated by theoretical calculation based on published information (e.g., manufacturers' websites) on thermal resistance (R-value) for each wall assembly layer. While this may be reasonable for preliminary designs, such estimation can lead to some "performance gap" or difference between the predicted performance and the real performance, as pointed out by De Wilde [3]. A more common case is that for retrofit projects of existing buildings, thermal properties of building assemblies are not well documented, and therefore, even theoretical calculation process may not be feasible if no information on wall details is available. Therefore, either laboratory or in-situ measurement of building envelope thermal transmittance would be the reasonable approach.

A significant amount of research studies has been focused on the measurement of $\mathrm{BE}$ thermal transmittance since the early 70 's. For laboratory measurement, the Hot Box 
Test Method (HBT) is still the most accurate method to measure an entire BE assembly, including any effect of thermal bridging. However, both variations of the HBT method, i.e., the Guarded Hot Box Method and the Calibrated Hot Box Method, require large testing facilities and mock-up assemblies, which is feasible for new construction, but quite a challenge for existing buildings. On the other hand, for in-situ measurement, the Heat Flow Meter Method (HFM) is available and has been used in some studies. Due to unstable environmental conditions for in-situ measurement, some researchers have been focusing on different models for data processing on site. While it is recognized that the use of dynamic models can improve the accuracy, there is no consensus on which model works better.

In the recent years, the application of Infrared Thermography (IRT) Method has been increasingly explored to measure the building envelope thermal transmittance on site. Unlike the HBT and the HFM, the IRT Method requires much less data logging equipment and data processing workload, and therefore becomes a more practical method for both academic and industrial projects. However, while there are some studies proposing several models for the IRT Method, the accuracy and feasibility of each IRT model remains unclear.

While each method has been studied and explored to some extent, a comprehensive review and comparison of the existing measurement methods for BE thermal transmittance has not been undertaken sufficiently, in particular, to introduce the new IRT method in relation to the existing and better known HBT and HFM methods. In this paper, these methods and some related previous research studies regarding the HBT, HFM, and IRT Methods are reviewed and compared to provide an overall understanding on the pros and cons of each method. More specifically, the concept and experimental design of HBT are introduced, following different dynamic models and data analysis methods for the in-situ HFM method. At the end, calculation model and benefits/limitations of IRT are illustrated.

\section{Thermal Transmittance Measurements: State of the Art}

\subsection{Hot Box Test Method}

For many years, the Hot Box Test Method (HBT) has served as a powerful tool to accurately measure the building envelope thermal transmittance in laboratory setting [4]. In the U.S., ASTM C1363 standard [5] is used to govern the measurement apparatus and procedures. A schematic view of the hot box setup is shown in Figure 1. There are typically two types of hot box tests: the guarded hot box and the calibrated hot box. The guarded hot box relies on the use of a metering chamber inside the guarded chamber. By keeping these two chambers at the same temperature, the heat loss through the metering chamber wall to the guarded chamber can be ignored. The calibrated hot box, on the other hand, regards the surrounding environment as the "guarded chamber" and therefore avoids the need to build an inside metering chamber. However, a known wall specimen is needed before any tests to calibrate the whole chamber.

According to ASTM C1363, the thermal transmittance $U$ is defined as:

$$
U=\frac{Q}{A \cdot\left(T_{e n v, h}-T_{e n v, c}\right)}
$$

where $Q$ is the heat flow passing through the specimen, $\mathrm{A}$ is the metering box opening area, $T_{e n v, h}$ and $T_{e n v, c}$ are the hot and cold side environmental temperatures. It should be noted that this equation includes the "surface coefficient" and therefore its reciprocal is not the surface-to-surface R-value, but the overall R-value instead.

One of the key rules to perform hot box tests is to keep constant temperature levels in both the metering and the climate chamber, while creating a certain temperature difference between the two chambers. As the HBT is based on steady-state calculation, it generally requires a long testing period to reach and maintain such chamber condition. The chamber walls need to be well-insulated to roughly maintain one-dimensional heat transfer. As shown in Figure 1, the hot box apparatus is able to measure an entire assembly including any thermal bridging effect, however, it also requires large testing chambers, a complete built-in data logging system and construction of mock-up assemblies. Therefore, it may 
cause inconvenience if thermal transmittance of existing assemblies is to be measured. A similar apparatus is called "Guarded Hot Plate", which adopts the same concepts and assumptions as HBT, but with a reduced scale and is therefore not commonly used for the entire building envelope assembly. The Guarded Hot Plate Method is explained in detail in ASTM C177 [6], and an example of its application to measure insulation materials is shown in Kobari et al.'s study [7].
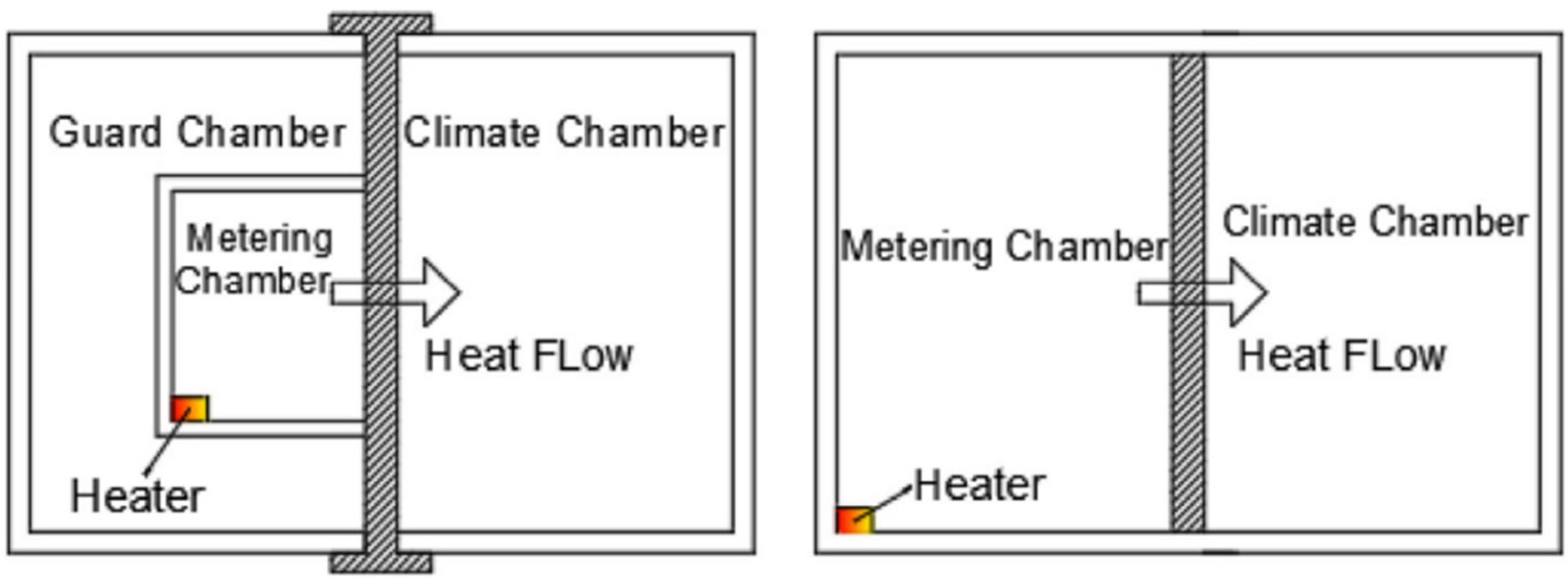

Figure 1. Schematic Hot Box Setup: Guarded Hot Box (left), Calibrated Hot Box (right).

Many efforts have been made to use hot box apparatus for building envelope thermal testing. Burch et al. [8] used a calibrated hot box apparatus to determine the transfer function coefficients for a given wall assembly. Elmahdy [9] measured heat transmission and the R-value of fenestration systems using a guarded hot box and proposed a detailed uncertainty analysis. Fang [10] measured the center-of-glass U-value for a window with a long-wave high-reflectivity venetian blind by using two side-by-side hot boxes. Wakili and Tanner [11] compared the U-values of a perforated porous clay brick wall obtained by HBT and numerical analysis in BISCO. Kossecka and Kosny [12] proposed two methods to estimate the minimum test time for HBT as the cost of performing hot box experiments for building envelope assemblies is relatively high. Martin et al. [13] studied the performance of wall assemblies with a reinforced concrete pillar as the thermal bridge area by using a typical guarded hot box apparatus. Zhao et al. [14] proposed a reduced-scale hot box apparatus to measure the U-value and thermal conductivity of window insulation materials, and the results are compared with commercially available values for validation. Trgala et al. [15] measured the U-values for several building envelope assemblies under dynamic conditions by calibrated hot box and compared the experimental values with the documented values from manufacturer or standard calculation.

\subsection{Heat Flow Meter Method}

The Heat Flow Meter Method (HFM) is a commonly used and standardized method for in-situ measurement of building envelope assemblies and is governed by ASTM C518 [16] and ASTM C1045 [17] standards in the U.S. It incorporates the use of on-site installation of temperature sensors and heat flux transducers (heat flux sensors) on existing building walls whose thickness is much smaller than the other dimensions, and therefore the lateral heat flow can be ignored. Similar to the HBT, the HFM is also based on steady-state assumption and a certain level of temperature difference between interior and exterior environments is essential. The most commonly used calculation method for HFM is the same as that shown in Equation (1), which is generally referred as the "Average Model", as stated in Deconinck and Roels [18]. However, unlike the HBT that has well-controlled laboratory environment, for HFM, environmental conditions can vary significantly and never reach quasi steady- 
state for in-situ measurement, and therefore may cause considerable inaccuracy using the Average Model even if a long test period is adopted, unless the thermal inertia of the tested assembly is relatively negligible. A good example to illustrate the variation of the Average Model is also shown in Deconinck and Roels's study [18]. Research has shown that to use the Average Model for in-situ HFM measurement, at least 14 days of measurement is needed to consider adequate, while still leading to a variance of 1-61\% [19]. Also, due to the use of heat flux sensors, the HFM method cannot account for the thermal bridge effect. Kim et al. [20] proposed an improved HFM method with the use of heat loss coefficient to take the thermal bridge effect into consideration. Several dynamic models have been developed and explored by different researchers [21,22], as discussed in the sections below. It should be noted that due to various types of dynamic models and sensors used for Heat Flow Meter Method, it is difficult to quantify and compare the accuracies of different studies. To address this issue, many efforts have been made to explore different calculation models for HFM and different models can lead to very different results. For example, $\mathrm{O}^{\prime}$ Hegarty et al. [22] performed in-situ measurement for highly-insulated building envelope systems with different HFM calculation methods, and the results showed differences of up to $300 \%$. Some research work has been focused on different dynamic models, which can be used on-site to eliminate the influence of unstable environmental conditions, while some other researchers proposed models without the use of a heat flux sensor. These models are further introduced in the following sections.

\subsubsection{The GullfibR Model (Anderlind's Regression Model)}

To consider the effect of unstable environmental conditions, the GullfilR Model regards the heat flux measurement at the $i$ th step $q_{i}$ in three separate parts. As shown in Equation (2), the first part is a steady-state heat transfer of the tested wall, with $R$ as the assembly thermal resistance to be calculated and $T_{i, \text { surf }}$, int and $T_{i, \text { surf, ext }}$ the interior and exterior surface temperature reading at the $i$ th step. The second part is to consider the influence of historical interior temperature changes on the current $i$ th heat flux measurement. The third part, on the other hand, is to consider the influence of historical exterior temperature changes on the current $i$ th heat flux measurement. $p$ is the number of historical temperature changes to consider in the calculation, while A's and B's are the regression coefficients. It can be observed from Equation (2) that the GullfilR Model regards the influence of thermal inertia of the tested assembly as an addition to the steady-state thermal performance and can be solved by multiple regression.

$$
\begin{aligned}
q_{i}=\frac{1}{R}\left(T_{i, \text { surf, int }}\right. & \left.-T_{i, \text { surf,ext }}\right) \\
+ & \sum_{l=1}^{p} A_{l}\left(T_{i-p+l, \text { surf, int }}-T_{i-p+l-1, \text { surf, int }}\right)+\sum_{l=1}^{p} B_{l}\left(T_{i-p+l, \text { surf, ext }}-T_{i-p+l-1, \text { surf, ext }}\right)
\end{aligned}
$$

The GullfibR Model is convenient for on-site data processing, and therefore more practical compared with other dynamic models. Users need to determine how many historical points $p$ to be used in the regression. Deconinck and Roels [18] show that the GullfibR Model leads to a fast and accurate convergence to the reference value, while Lu and Memari [21] proposed that the calculated R-value from GullfibR Model shows less than $5 \%$ difference compared with the reference value. It should be noted that as [18] pointed out, the GullfibR Model assumes a zero intercept in regression, and therefore the $R^{2}$ value is not a good statistical indicator for the goodness of fit of the regression results.

An improved version of the GullfibR Model is called the Pentaur Model, which was also proposed by Anderlind [23]. The Pentaur Model is expressed in Equation (3). Like the GullfibR Model, the Pentaur Model is also based on the assumption that the historical changes in environmental conditions have an influence on the current heat flux measurement in a linear form. However, the Pentaur Model also includes the historical changes in the heat flux passing through the assembly and takes it into consideration for the current $i$ th heat flux measurement. Therefore, it has the potential to deal with more complicated situations where the environmental radiation/convection changes with 
time during the test. It should also be noted that as the "Pentaur Model" is not an officially published name, it was mentioned in [24], but the authors were referring to the GulfibR Model.

$$
\begin{aligned}
q_{i}=\frac{1}{R} \quad\left(T_{i, \text { surf, }}\right. \text { int } & \left.-T_{i, \text { surf }, \text { ext }}\right) \\
& +\sum_{l=1}^{p} A_{l}\left(T_{i-p+l, \text { surf }, \text { int }}-T_{i-p+l-1, \text { surf, int })}\right)+\sum_{l=1}^{p} B_{l}\left(T_{i-p+l, \text { surf, ext }}-T_{i-p+l-1, \text { surf, ext }}\right) \\
& +\sum_{l=1}^{p} C_{l}\left(q_{i-p+l}-q_{i-p+l-1}\right)
\end{aligned}
$$

\subsubsection{ARX-Model}

ARX-Model is another type of dynamic model that can be used to calculate the building envelope R-values from in-situ data. It is also called the "black-box" model as it is based on statistical autoregressive approach. In other words, these models are mostly data-driven to minimize the input-output behavior of the constructed system, and the parameters in the models do not necessarily have internal physical relations [18]. An example formulation of ARX-Model is shown in Equation (4).

$$
T_{i, \text { int }}=\sum_{k=1}^{m} \beta_{k} T_{i-k, i n t}+\sum_{k=0}^{n} \gamma_{k} T_{i-k, e x t}+\sum_{k=0}^{p} \delta_{k} q_{i-k}+\varepsilon_{i}
$$

where subscript $i$ refers to the $i$ th step, $T_{i, \text { int }}$ is the interior temperature, $T_{i, \text { ext }}$ is the exterior temperature, and $q_{i}$ is the heat flux, all at the $i$ th step. The parameter $\varepsilon$ is an error term, while $\beta$ and $\gamma$ are regression parameters [25].

It can be observed that the key concept to use the ARX-Model for building envelope thermal properties is to build some statistical relations among the measured interior temperature, exterior temperature, and heat flux. The input and output quantities in Equation (4) are not fixed, as shown in [18] where the authors used the heat flux as the output instead of interior temperature. The authors also pointed out that while the parameters in ARX-Model do not have physical meanings, one can calculate the building envelope thermal resistance by comparing the ARX-Model formulation and the steady-state heat transfer equation. Jiménez et al. [26] explored several ARX-Models with different inputs and outputs by MATLAB IDENT toolbox and found very good performance for multi-output models giving low identification errors. Deconinck and Roels [18] did an in-depth introduction regarding how to relate the ARX-Model formulations to real-world physical quantities, i.e., thermal resistances. Madsen et al. [27] pointed out that averaging the measured data, which serves as a low pass filter, is suggested for ARX-Model.

It should be noted that the Pentaur Mreviseodel discussed in Section 2.2.1 can be regarded as a specific form of ARX-Model with the steady-state performance inserted into the model formulation. Both are based on multiple linear regression, which is a relatively easy and straightforward way for data processing compared with the state-space models introduced in Section 2.2.1. As Teni et al. [28] mentioned, such dynamic models that are more time-consuming and complex compared with the Average Model tend to be less sensible to the test period and therefore can provide shorter necessary measurement time span with more accurate results for in-situ measurement.

\subsubsection{R-C Network Model}

The R-C Network Model is a typical dynamic models used for in-situ measurement of building envelope thermal properties. Compared to the ARX-Model, the R-C Network Model is also called the "grey-box" model as its model formulation and parameters are based on physical correlations instead of being purely data-driven. A schematic view of an R-C Network Model is shown in Figure 2. It can be observed that the R-C Network Model is based on an analogy to electric circuit, with the heat flux passing through the wall regarded as electric current. It adopts a lumped capacitance assumption, meaning that the 
overall thermal resistance can be treated as separate resistances $R_{1}, R_{2}, \ldots$ in series, and likely the overall thermal capacitance. The end nodes $T_{\text {int }}$ and $T_{\text {ext }}$ are the interior and exterior temperatures. It should be noted that each layer in the R-C Network Model, i.e., $R_{1}, R_{2}, \ldots$, is conceptual and does not represent the physical layers inside the wall.

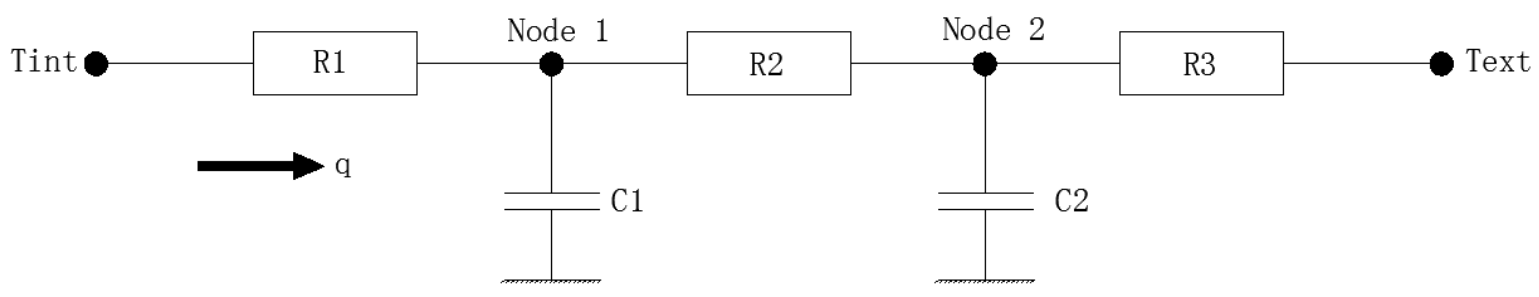

Figure 2. A 3R2C Network Model.

Based on the energy balance at each node in Figure 2, the model can be formulated as:

$$
\begin{aligned}
& C_{1} \frac{d T_{1}^{i}}{d t}=\frac{T_{i n t}^{j}-T_{1}^{i}}{R_{1}}-\frac{T_{1}^{i}-T_{2}^{i}}{R_{2}} \\
& C_{2} \frac{d T_{2}^{i}}{d t}=\frac{T_{1}^{i}-T_{2}^{i}}{R_{2}}-\frac{T_{2}^{i}-T_{\text {ext }}^{i}}{R_{3}}
\end{aligned}
$$

And the heat flux input can be expressed as:

$$
q^{i}=\frac{1}{R_{1}}\left(T_{i n t}^{i}-T_{1}^{i}\right)
$$

By reorganizing Equations (5)-(7) we get the matrix form of the above state-space equations:

$$
\begin{gathered}
{\left[\begin{array}{c}
\frac{d T_{1}^{i}}{d t} \\
\frac{d T_{2}^{i}}{d t}
\end{array}\right]=\left[\begin{array}{cc}
-\frac{1}{C_{1} R_{1}}-\frac{1}{C_{1} R_{2}} & \frac{1}{C_{1} R_{2}} \\
\frac{1}{C_{2} R_{2}} & -\frac{1}{C_{2} R_{2}}-\frac{1}{C_{2} R_{3}}
\end{array}\right]\left[\begin{array}{c}
T_{1}^{i} \\
T_{2}^{i}
\end{array}\right]+\left[\begin{array}{cc}
\frac{1}{C_{1} R_{1}} & 0 \\
0 & \frac{1}{C_{2} R_{3}}
\end{array}\right]\left[\begin{array}{c}
T_{i n t}^{i} \\
T_{\text {ext }}^{i}
\end{array}\right]} \\
q=\left[\begin{array}{ll}
-\frac{1}{R_{1}} & 0
\end{array}\right]\left[\begin{array}{c}
T_{1}^{i} \\
T_{2}^{i}
\end{array}\right]+\left[\begin{array}{ll}
\frac{1}{R_{1}} & 0
\end{array}\right]\left[\begin{array}{c}
T_{i n t}^{i} \\
T_{\text {ext }}^{i}
\end{array}\right]
\end{gathered}
$$

Equations (8) and (9) represent the general form of a 3R2C Network Model. As can be observed, the parameters in the above equations have direct physical meanings related to the thermal properties. These parameters can be estimated by grey-box estimation using maximum likelihood algorithm. Therefore, the overall R-value of the wall is equal to the summation of all separate $\mathrm{R}^{\prime} \mathrm{s}$ parameters. The input and output quantities are interchangeable and not necessarily the same as in the equations above. It should be noted that Wiener Process and Gaussian white noise can also be added to Equations (5)-(7) to represent the unpredicted errors during measurement, making it a stochastic state-space model, as indicated in $[18,29]$.

The advantage of using the R-C Network Model is that it is based on the physical energy balance equation at each node and represents the real physical process. Therefore, any other influencing factors that may have an effect on the results, such as the solar radiation, can be added to the model by introducing additional terms at different nodes. Besides, by utilizing the stochastic state-space form, any unpredicted error during the measurement process can be taken into consideration. Deconinck and Roels [18] have demonstrated that the R-C Network Model is reliable for in-situ measurement and have found that over short time periods, the GullfibR Model has a slightly faster convergence and accuracy compared with the ARX-Model and R-C Network Model, but for long periods, the ARX-Model and R-C Network Model turn out to be more accurate. Jiménez et al. [29] pointed out that such linear approximations in the R-C Network Model 
are suitable for understanding nonlinear building envelope performance. Deconinck and Roels's study [30] showed that using the R-C Network Models, the R-value can be estimated within a 5-10\% accuracy. Fonti et al. [31] further studied the performance of R-C Network Model from the first-order to the third-order and found that the second-order model tends to have the best accuracy.

However, it should be noted that the application of R-C Network Model is more labor intensive compared with the GullfibR Model and the ARX-Model, and it requires more background understanding in statistics and programming. Another problem that needs more research effort is the choice of initial values to solve the state-space equations. Different choices of initial values may have a large influence on the convergence rate and the final result of the grey-box estimation process and therefore should be carefully treated.

\subsubsection{Air-Surface Temperature Ratio Method}

As mentioned in the previous sections, errors in the test result of in-situ measurement can come from various sources, including the accuracy of heat flux measurement. In fact, the heat flux is a relatively more sensitive quantity to measure compared with temperature and relative humidity. Due to the unstable condition for in-situ measurement, it can be difficult to figure out the real source that causes fluctuation in the measured heat flux at a certain time period. Therefore, some research studies have been conducted to measure the building envelope U-values without the use of heat flux sensors. Bienvenido-Huertas et al. [32] proposed a study using the Air-Surface Temperature Ratio Method (also called the Thermometric Method) to measure the U-value on site. For quasi steady-state conditions, the interior convective heat transfer can be expressed by Newton's Law of Cooling:

$$
q=h_{\text {in }}\left(T_{\text {int }}-T_{\text {surf }, \text { int }}\right)
$$

where $q$ is the heat flux, $h_{\text {in }}$ is the interior convective heat transfer coefficient, $T_{\text {int }}$ is the interior air temperature and $T_{\text {surf,int }}$ is the interior surface temperature. Then the U-factor for the tested wall can be calculated as in Equation (11):

$$
U=\frac{q}{T_{\text {int }}-T_{\text {ext }}}
$$

where $T_{\text {ext }}$ is the exterior air temperature. Combining Equation (10) with Equation (11), the U-factor can be expressed as in Equation (12):

$$
U=\frac{h_{\text {in }}\left(T_{\text {int }}-T_{\text {surf }, \text { int }}\right)}{T_{\text {int }}-T_{\text {ext }}}
$$

Equation (12) serves as the calculation basis for Air-Surface Temperature Ratio Method. Since the heat flux is not a necessary quantity to be measured for such a method, the data analysis process and the in-situ equipment setup can be significantly simplified, making it a faster and more practical way for in-situ measurement. Bienvenido-Huertas et al. [32] proposed that the Air-Surface Temperature Ratio Method shows a good performance in winter, with relative uncertainties between $6 \%$ and $13 \%$. The authors also conclude that during summer or autumn the associated uncertainties for using this method would be unacceptable. Kim et al. [33] confirmed the feasibility and accuracy of the Air-Surface Temperature Ratio Method and state that a quasi steady-state condition would be essential to guarantee an acceptable accuracy level for this method. In another study, Kim et al. [34] found that the relative measurement error between the Average Model and the Air-Surface Temperature Method is about 3\%.

It is worth mentioning that while the Air-Surface Temperature Ratio Method has been verified by existing studies, it can cause some problems under certain conditions. In Equation (12), it can be observed that when calculating the U-value, the interior radiative heat transfer process is not taken into consideration. It means that the Air-Surface Tem- 
perature Ratio Method has an underlying assumption that all interior surfaces are of the same temperature. Such an assumption can lead to neglecting potential measurement error especially when there are indoor heat sources. Moreover, the $h_{\text {in }}$ value in Equation (12) comes directly from ISO standard in the existing studies. The recommended interior convective heat transfer coefficient in ISO standard $\left(10 \mathrm{~W} / \mathrm{m}^{2} \mathrm{~K}\right.$ for upward flow, $7.69 \mathrm{~W} / \mathrm{m}^{2} \mathrm{~K}$ for horizontal flow, and $5.88 \mathrm{~W} / \mathrm{m}^{2} \mathrm{~K}$ for downwards flow) is an approximation and may not be suitable for all interior conditions and building geometries. Evangelisti et al. [35] compared the Average Model and the Air-Surface Temperature Ratio Method and found that the convective heat transfer coefficient can significantly influence the result, leading to a difference in heat flux from 35.8 to $174 \%$. Therefore, it is always suggested to measure the indoor convective heat transfer coefficient on site for improved accuracy. It should also be noted that the Air-Surface Temperature Ratio Method is not a dynamic model; therefore, its application highly relies on the quasi steady-state measurement condition and a relatively long testing period, as pointed out by Kim et al. [33,34].

An improved version of the Air-Surface Temperature Ratio Method is proposed by Jankovic et al. [36], which is referred to as "Natural Convection and Radiation Method (nCaR)". In addition to Equation (12), the nCaR Method also takes the interior radiative heat transfer process into consideration, and therefore the U-factor is calculated as follows:

$$
U=\frac{h_{\text {in }}\left(T_{\text {int }}-T_{\text {surf }, \text { int }}\right)+\varepsilon \cdot \sigma\left(T_{\text {int }}^{4}-T_{\text {surf }, \text { int }}^{4}\right)}{T_{\text {int }}-T_{\text {ext }}}
$$

where $\varepsilon$ is the surface emissivity and $\sigma$ is the Stefan-Boltzmann's constant.

Equation (13) incorporates the Stefan-Boltzmann's Law to calculate the amount of radiative heat transfer, and therefore makes it more accurate compared with the Air-Surface Temperature Ratio Method. Jankovic et al. [36] indicated from the measured data that the $\mathrm{nCaR}$ Method shows a smaller mean absolute deviation (16.8\%) compared to the Average Model (19.3\%). Given that [36] utilized an infrared camera for temperature measurement, the $\mathrm{nCaR}$ Method can also be regarded as a certain type of Infrared Thermography Method (IRT), which is further introduced in Section 4.

\subsubsection{Simple Hot Box-Heat Flow Meter Method}

To address the unstable test conditions for in-situ measurement, various research studies have been focused on multiple solutions. Some researchers explored different types of dynamic models, which reduce the dependence of results on test conditions and period, while others came up with on-site test equipment that can provide better in-situ measurement conditions. The Simple Hot Box-Heat Flow Meter Method (SHB-HFM) is proposed to guarantee a controlled environment on site, which is similar to the HBT in laboratory [37]. A schematic view of the simple hot box setup is shown in Figure 3. This method has the same theoretical basis as that described in Equation (1); however, it combines the advantages of the guarded HBT method and HFM principles [28]. An enclosed hot box is attached to the warmer side of the wall with an internal heating equipment. As the wall surface inside the box can be uniformly heated, this setup creates a quasi steady-state heat transfer with a guaranteed temperature difference, and therefore Equation (1) can be applied. Meng et al. [37] proposed that the SHB-HFM leads to a higher accuracy than the HFM Average Model, with test error of about 6\% even under the most unfavorable in-situ conditions, and overcomes the seasonal limitations of HFM Average Model. Scarpa et al. [38] confirmed that the SHB-HFM shortens the measurement period and allows users to perform in-situ measurement even in the warm climate. Meng et al. [39] further studied the SHB-HFM and proposed that increasing the controlled temperature difference can significantly decrease the test error. The authors also indicated that the SHB-HFM has remarkable significance especially when measurement conditions are poor. 


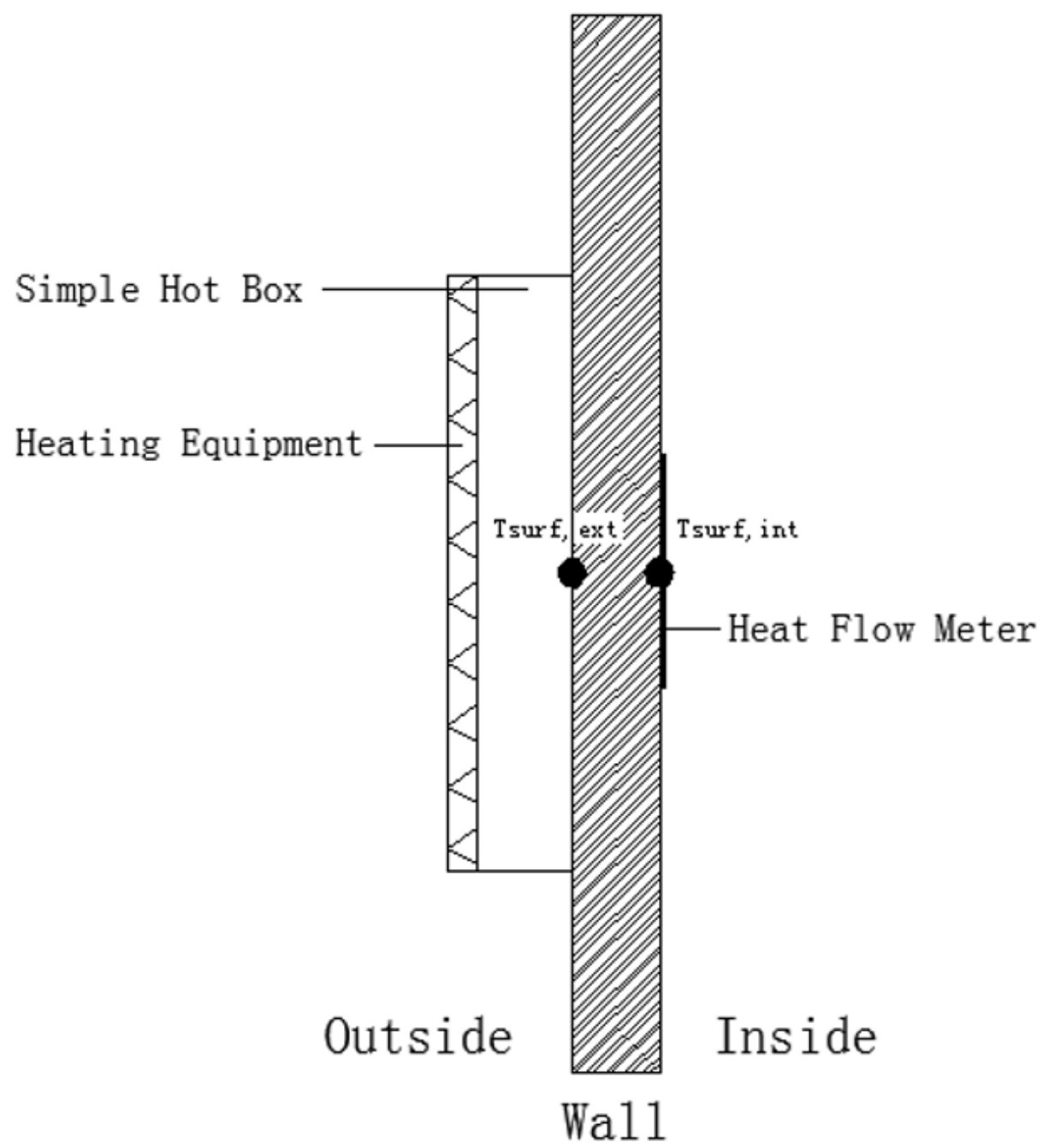

Figure 3. Schematic View of the Simple Hot Box Setup in Summer Condition.

It should be noted that as pointed out by Teni et al. [28], the SHB-HFM Method is relatively new and has only been explored under summer conditions with respect to limited types of walls. Therefore, even though high accuracy has been reached in the existing studies, research is still lacking regarding its reliability and applicability and more case studies are desired in the future.

In general, the Heat Flow Meter Method is applicable for in-situ measurement and there is no need for large testing chambers and mock-up specimens. Sensors and the data acquisition system can be directly mounted on the existing walls, and the method provides a faster way for engineers and researchers compared with the Hot Box Test Method. On the other hand, the non-steady state testing condition can largely influence the accuracy of Heat Flow Meter Method. While dynamic models can be used to eliminate such an influence, these applications are not commonly recognized and standardized. For example, very limited studies are available regarding the choice of initial values for R-C Network, which can greatly influence the estimated $\mathrm{R}$-value. The use of dynamic models also requires more complicated data processing compared with the Hot Box Test Method. And just like the Hot Box Test Method, the locations of sensors need to be carefully selected to avoid thermal bridging areas, such as studs, insulation voids, corners, etc.

\subsubsection{Infrared Thermography Method}

For many years, Infrared Thermography (IRT) has been used as a qualitative method for building inspection and diagnose. In the industry, it has been widely used as a supplemental tool to locate surface defection and thermal bridge areas. By detecting the radiative 
power received by the camera, IRT is able to provide users the complete profile over an entire surface, therefore making it suitable to be used quantitatively for the measurement of building envelope U-factor. Research on the IRT Method to measure the building envelope U-factor has been growing more extensively in the recent years. Most research work is focused on the use of indoor IRT Method, given the fact that indoor conditions are more stable. However, indoor IRT requires full access to the building, which may not be suitable for all cases. Therefore, the outdoor IRT Method is also of interest, as it does not require access to the building interior.

The theoretical basis for indoor IRT Method is the same as that in Equation (13). The surface temperature is given by the infrared camera, and with appropriate choice of the convective heat transfer coefficient, the U-factor can be calculated. For the measurement of air temperature, there are multiple ways. Some researchers have used additional thermocouples to measure the air temperature, while others have explored the use of infrared camera to measure both the air and wall surface temperatures in order to minimize the measurement error caused by different equipment.

Madding [40] proposed a complete measurement procedure and calculation model for indoor IRT Method. The author also proposed a process to estimate the air temperature and reflected temperature by using the infrared camera. The reflected temperature is a necessary input for correctly interpreting the information in thermal images. The author used empirical correlations to estimate the interior convective heat transfer coefficient, while using a default surface emissivity value of 0.95 . While the result shows a low uncertainty level, it should be noted that the study was based on a one-day measurement, and that the author did not present any validation of the accuracy based on other measurement methods.

Fokaides and Kalogirou [41] studied the indoor IRT by performing in-situ measurement in winter and summer and validated the results with both theoretical calculation and HFM Method. The results show a good agreement between the U-factors obtained by the IRT and HFM Methods. However, the authors indicated that roof and glazing areas show larger deviation due to the thermal inertia effect. In this study, the authors proposed a step-by-step method to measure the reflected temperature by infrared camera using a crumpled and re-flattened aluminum foil.

Tejedor et al. [42] proposed a different indoor IRT Method to use the dimensionless approach to estimate the interior convective heat transfer coefficient. The results show that the difference between the proposed method and the calculated U-factor ranges from 1.24\% to $3.97 \%$, while the HFM Method shows a difference of $14 \%$ to $28 \%$. In contrast with other indoor IRT Methods, the proposed method allows a temperature difference of $7{ }^{\circ} \mathrm{C}$. The authors mention that the study is based on heavy walls, and that for light walls that have less thermal inertia, the result could be different as the influence of wind speed is higher.

Marshall et al. [43] studied the variations of U-factors measured by indoor IRT Method for a whole residential building and the corresponding difference in the estimated building energy performance. The authors explored the application of low-resolution IRT and high-resolution IRT and pointed out that while being more informative, the variation of U-factors obtained from the IRT method is larger than that resulting from the HFM Method. It should be noted that while the authors applied building energy modeling in DesignBuilder, the U-factor itself obtained from the IRT method may not be sufficient to recognize a difference in building energy performance, as the building energy modeling incorporates many influencing factors such as the building envelope thermal capacity, which is not measured by the IRT Method.

In 2018, an ISO standard was published [44] to standardize the testing equipment, process and calculation model for the indoor IRT Method for frame structure dwellings. This standard incorporates the use of heat transfer coefficient sensor, environmental temperature sensors and thermocouples, and it states that this indoor IRT Method only applies during night conditions. It also mentions that because the temperature of exterior building surfaces strongly depends on the solar radiation during daytime and varies significantly with time, and that the exterior convective heat transfer coefficient also strongly depends 
on the wind velocity, the outdoor IRT method is not applicable. However, this standard is based on research work prior to 2007 and does not include the most up-to-date IRT related research. Recent studies such as Lu and Memari [24] have recognized and explored ways to overcome these difficulties for outdoor IRT application.

As for the outdoor IRT Method, the application tends to be more complex. The advantage of outdoor IRT is that it requires very little or no accessibility to the indoor building environment and therefore interrupts the residents' activities to the minimum extent. According to the existing studies, the calculation model is similar to Equation (13), replacing the use of interior temperatures with exterior temperatures. Albatici and Tonelli [45] proposed a study that is focused specifically on the outdoor IRT Method with systematic ways to measure the surface emissivity and outdoor air temperature. Case studies were performed and the authors validated the results with HFM Method incorporating both Average and Dynamic Models. The authors pointed out that the IRT Method has two main advantages: being fast enough and being able to consider the whole thermal characteristics of the tested wall. It should be noted that in this study, the outdoor convective heat transfer coefficient was considered by a truncated version of the Jurges' equation, while the simplification is purely data-driven and has no theoretical basis. The authors further validated this method in another study [46] and concluded that the outdoor IRT Method has the advantages of being rapid, non-invasive, non-destructive, and with the exception of wind speed measurement, able to use the same instrument for the whole test process.

Dall'O' et al. [47] performed outdoor IRT in-situ measurement for 14 existing buildings in Italy. Assuming a surface emissivity value of 0.90 for all cases, the authors indicate that the percentage difference between the calculated and measured U-factors is acceptable for solid-mass buildings but increases significantly for well-insulated buildings. They also point out that compared with the outdoor IRT Method, the HFM Method is more expensive in execution time and data processing.

Nardi et al. [48] validated the outdoor IRT Method by using a hot box test apparatus using the same model as [45]. The results show a reasonable agreement between the explored methods with percentage difference ranging from $3.23 \%$ to $12.9 \%$. The authors also indicate that for such tests, the optimum temperature difference between interior and exterior environments must be almost $20^{\circ} \mathrm{C}$. The authors further compare the outdoor IRT Methods in another study [49] using several different calculation models that had been published. In that study, the authors conclude that increasing the temperature difference can make the results more stable, and that low difference between reflected and outdoor air temperature is preferable, which can be achieved in fully overcast days.

Simões et al. [50] explored the use of outdoor IRT Method under laboratory condition and compared the results with HFM Method. The authors show that the worst relative error between the IRT Method and the calculated U-value would be about $37 \%$ while the HFM shows a worst case up to $45 \%$. It should be noted that in that study, the wind speed is treated as a constant under controlled conditions. Furthermore, the sensitivity analysis indicated that lower errors can be reached with lower emissivity, wind speed and reflected temperature values.

It is worth mentioning that all the outdoor IRT studies discussed above used the Jurges' equation to estimate the exterior convective heat transfer coefficient. However, as mentioned earlier, the truncated Jurges' equation does not have a solid theoretical basis. Watmuff et al. [51] also noted that the Jurges' equation could be inaccurate in estimating the convective heat transfer by including the radiation effect. The choice of exterior convective heat transfer coefficient can significantly influence the results, and therefore, more realistic ways to calculate the exterior convective heat transfer coefficient is needed. It should also be noted that while most of the existing outdoor IRT studies also take Equation (13) as the calculation basis, such equation can cause error for outdoor application as it has an underlying assumption of the unity view factor. As pointed out by [40], the sky temperature can be significantly different from the ambient air temperature, and therefore, while being acceptable for indoor IRT Method, the unity view factor assumption is not suitable for 
outdoor application. To address these issues, Lu and Memari [24] conducted in-situ measurement for a low-rise residential building and proposed a more comprehensive calculation model expressed in Equation (14).

$$
U=\frac{F_{\text {gnd }} \varepsilon \sigma\left(T_{\text {surf }}^{4}-T_{\text {gnd }}^{4}\right)+F_{\text {sky }} \varepsilon \sigma\left(T_{\text {surf }}^{4}-T_{\text {sky }}^{4}\right)+F_{\text {air }} \varepsilon \sigma\left(T_{\text {surf }}^{4}-T_{\text {ext, air }}^{4}\right)+h_{c}\left(T_{\text {surf }}-T_{\text {ext, air }}\right)}{T_{\text {int, air }}-T_{\text {ext, air }}}
$$

where $T_{\text {int, air }}$ and $T_{\text {ext, air }}$ are the indoor and outdoor air temperatures. $T_{\text {gnd }}$ is the ground temperature and $T_{s k y}$ is the sky temperature. $F_{g n d}, F_{s k y}$ and $F_{a i r}$ are the view factors of ground, sky and ambient air. The authors also proposed a new empirical correlation for the exterior convective heat transfer coefficient based on in-situ measurement. It should be noted that a night sky cooling effect was observed during measurement, meaning that the surface temperature drops below the ambient air temperature, and therefore Equation (13) cannot be applied. Such a phenomenon has not been addressed in previous studies and may be considered by using Equation (14). In addition, Bienvenido-Huertas et al. [52] explored different ways to estimate the exterior convective heat transfer coefficient aside from the Jurges' equation.

\section{Discussions and Comparisons}

As mentioned above, the Hot Box Test Method can generally provide accurate measurement results due to its steady-state testing conditions. It also does not require complicated post-test data processing techniques. However, the need for a large testing chambers and mock-up testing specimens makes it difficult to be applied to projects when thermal testing is desired, especially for retrofit projects of existing buildings where the existing wall assembly is unknown-a common case for real-world projects. Locations of sensors should also be carefully selected to avoid thermal bridging areas, which can also be difficult for unknown assemblies. Therefore, for on-site measurement of the building envelope thermal transmittance, the Heat Flow Meter Method is preferred.

For Heat Flow Meter Method, by using portable heat flux sensors it allows in-situ measurement of existing building envelope components. It can also take the transient thermal performance of building envelope components into consideration with the use of different dynamic models such as the R-C Network models. However, it should be noted that uncertainties of in-situ measurement come from many factors and are not only due to the unstable measurement conditions. One error source that could often be ignored is the accuracy of hardware. For most commercially available heat flux sensors used for in-situ measurement, such as the Hukseflux HFP 01, the sensitivity of sensors usually lies in the range of microvolts, which means that if one uses some microchips, such as Arduino or Raspberry Pi, the analog-digital converter (ADC) should be able to read the data in the level of microvolts. For example, if Arduino is used for data logging with a voltage supply of $0-5 \mathrm{~V}$, an external ADC of 24 bits is necessary specifically for reading the data from heat flux sensors. While temperature sensors generally require much less accuracy from $\mathrm{ADC}$, this specific requirement can lead to large variation in the measurement results. A detailed description of such experimental setup can be found in [21]. Since the accuracy and influencing factors of heat flux sensors are barely explored and discussed in this area, comparison of the performance of dynamic models used in different research studies can be a challenge.

The use of Infrared Thermography Method provides a quick and practical alternative to in-situ measurement of building envelope thermal transmittance. Unlike using spotmeasurement sensors such as thermistors or heat flux sensors, the Infrared Thermography Method uses an infrared camera, which provides the potential to take thermal bridge effect into consideration and avoid any inhomogeneous areas during measurement. The drawback of such a method, however, is that currently there is no standard calculation model, and as mentioned earlier, the influence of sky temperature and ground temperature is barely taken into consideration in most of the studies, and therefore, more repeated tests are needed to validate different IRT models and results. 


\section{Summary and Conclusions}

This paper provided a comparison of the established and more recent methods to measure the building envelope thermal transmittance. Specifically, the Hot Box Test Method, the Heat Flow Meter Method and the Infrared Thermography Method were discussed. The Hot Box Test Method provides a stable and accurate approach for laboratory measurement, but is not suitable for in-situ measurement of existing buildings. The Average Model can be used as a model for in-situ measurement by Heat Flow Meter Method, but due to the unstable environmental conditions, the results may not be accurate. The measurement of heat flux, which is a more sensitive quantity compared with temperature, could also cause some errors. To address these issues, different dynamic models and testing facilities are explored and introduced in Section 3. The use of dynamic models, on the other hand, requires more complicated post-test data processing and some of the details during data processing remain unclear, such as the initial values for solving the R-C Network Model. In recent years, the Infrared Thermography has been studied as a quantitative tool for in-situ measurement of building envelope thermal transmittance. Different calculation models have been proposed for both indoor and outdoor IRT Method, and the advantages and shortages of these models are discussed in Section 4. The Infrared Thermography Method can serve as a quick and practical tool to measure the thermal transmittance for building envelope systems while providing relatively accurate results. With the building energy efficiency being increasingly an important design requirement, thermal performance of buildings has become a trending and dominating topic. Future work should be focused on addressing the modelling limitations/instrumentations of the current HFM method, as well as building up a comprehensive and standardized testing protocol for the in-situ IRT method. Needless to say, more research work is also desired for more quick and practical methods to measure the building envelope thermal properties especially for medium and high-rise buildings.

Author Contributions: Conceptualization, X.L. and A.M.M.; Methodology, X.L. and A.M.M.; Software, X.L.; Validation, X.L. and A.M.M.; Formal analysis, X.L. and A.M.M.; Investigation, X.L. and A.M.M.; Data curation, X.L. and A.M.M.; Writing—original draft preparation, X.L.; Writing—review and editing, A.M.M.; Project administration, A.M.M. All authors have read and agreed to the published version of the manuscript.

Funding: This research received no external funding.

Institutional Review Board Statement: Not applicable.

Informed Consent Statement: Not applicable.

Data Availability Statement: Not applicable.

Conflicts of Interest: The authors declare no conflict of interest.

$\begin{array}{ll}\text { Nomenclature } \\ \text { Symbol } & \text { Meaning } \\ \text { BE } & \text { Building Envelope } \\ \text { R-value } & \text { Thermal Resistance } \\ \text { HBT } & \text { Hot Box Test Method } \\ \text { HFM } & \text { Heat Flow Meter Method } \\ \text { IRT } & \text { Infrared Thermography Method } \\ U & \text { Thermal transmittance } \\ Q & \text { Heat flow } \\ T & \text { Temperature } \\ \text { int } & \text { Interior } \\ \text { ext } & \text { Exterior } \\ \text { surf } & \text { Surface } \\ C & \text { Thermal Capacitance } \\ h & \text { Convective transfer coefficient } \\ q & \text { Heat flux }\end{array}$




\section{References}

1. Kamel, E.; Memari, A.M. Different methods in building envelope energy retrofit. In Proceedings of the 3rd Residential Building Design \& Construction Conference, University Park, PA, USA, 2-3 March 2016; p. 21.

2. Stone, A.; Shipworth, D.; Biddulph, P.; Oreszczyn, T. Key factors determining the energy rating of existing English houses. Build. Res. Inf. 2014, 42, 725-738. [CrossRef]

3. De Wilde, P. The gap between predicted and measured energy performance of buildings: A framework for investigation. Autom Constr. 2014, 41, 40-49. [CrossRef]

4. Mumaw, J.R. Calibrated hot box: An effective means for measuring thermal conductance in large wall sections. In Heat Transmission Measurements in Thermal Insulations, ASTM STP 544; ASTM: West Conshohocken, PA, USA, 1974; pp. 193-211.

5. ASTM C1363; Standard Test Method for Thermal Performance of Building Materials and Envelope Assemblies by Means of a Hot Box Apparatus. American Society for Testing Materials (ASTM): West Conshohocken, PA, USA, 2014. [CrossRef]

6. ASTM C177; Standard Test Method for Steady-State Heat Flux Measurements and Thermal Transmission Properties by Means of Guarded-Hot-Plate Apparatus. American Society for Testing Materials (ASTM): West Conshohocken, PA, USA, 2013. [CrossRef]

7. Kobari, T.; Okajima, J.; Komiya, A.; Maruyama, S. Development of guarded hot plate apparatus utilizing Peltier module for precise thermal conductivity measurement of insulation materials. Int. J. Heat Mass Transf. 2015, 91, 1157-1166. [CrossRef]

8. Burch, D.; Zarr, R.; Licitra, B. A Dynamic Test Method for Determining Transfer Function Coefficients for a Wall Specimen Using Calibrated Hot Box. ASTM Symp. Insul. Mater. Test. Appl. 1990, 9, 345-361. Available online: https://www.astm.org/stp23317s. html (accessed on 24 January 2022).

9. Elmahdy, A.H. Heat transmission and R-value of fenestration systems using IRC Hot Box: Procedure and uncertainty analysis. ASHRAE Trans. 1992, 98, 630-637.

10. De Fang, X. A study of the U-factor of the window with a high-reflectivity Venetian blind. Sol. Energy 2000, 68, 207-214. [CrossRef]

11. Wakili, K.G.; Tanner, C. U-value of a dried wall made of perforated porous clay bricks: Hot Box measurement versus numerical analysis. Energy Build. 2003, 35, 675-680. [CrossRef]

12. Kossecka, E.; Kosny, J. Hot-box testing of building envelope assemblies-A simplified procedure for estimation of minimum time of the test. J. Test. Eval. 2008, 36, 100795. [CrossRef]

13. Martin, K.; Campos-Celador, A.; Escudero, C.; Gómez, I.; Sala, J. Analysis of a thermal bridge in a guarded Hot Box testing facility. Energy Build. 2012, 50, 139-149. [CrossRef]

14. Zhao, X.; Mofid, S.A.; Al Hulayel, M.R.; Saxe, G.W.; Jelle, B.P.; Yang, R. Reduced-scale hot box method for thermal characterization of window insulation materials. Appl. Therm. Eng. 2019, 160, 114026. [CrossRef]

15. Trgala, K.; Pavelek, M.; Wimmer, R. Energy performance of five different building envelope structures using a modified Guarded Hot Box apparatus-Comparative analysis. Energy Build. 2019, 195, 116-125. [CrossRef]

16. ASTM C518; Standard Test Method for Steady-State Thermal Transmission Properties by Means of the Heat Flow Meter Apparatus. ASTM International: West Conshohocken, PA, USA, 2015. [CrossRef]

17. ASTM C1045; Standard Practice for Calculating Thermal Transmission Properties under Steady-State Conditions. Annual Book of ASTM Standards. ASTM: West Conshohocken, PA, USA, 2012. [CrossRef]

18. Deconinck, A.-H.; Roels, S. Comparison of characterisation methods determining the thermal resistance of building components from onsite measurements. Energy Build. 2016, 130, 309-320. [CrossRef]

19. Doran, S. Safety and Health Business Plan: Field Investigations of the Thermal Performance of Construction Elements as Built; BRE Client Report No. 78132; BRE, Building Research Establishment Ltd.: Watford, UK, 2000.

20. Kim, S.; Seo, J.; Jeong, H.; Kim, J. In situ measurement of the heat loss coefficient of thermal bridges in a building envelope. Energy Build. 2021, 256, 111627. [CrossRef]

21. Lu, X.; Memari, A.M. Comparative study of Hot Box Test Method using laboratory evaluation of thermal properties of a given building envelope system type. Energy Build. 2018, 178, 130-139. [CrossRef]

22. O'Hegarty, R.; Kinnane, O.; Lennon, D.; Colclough, S. In-situ U-value monitoring of highly insulated building envelopes: Review and experimental investigation. Energy Build. 2021, 252, 111447. [CrossRef]

23. Anderlind, G. Multiple Regression Analysis of Thermal Measurements-Study of an Attic Insulated with $800 \mathrm{~mm}$ Loose. J. Build. Phys. 1992, 61, 81-104. [CrossRef]

24. Lu, X.; Memari, A. Application of infrared thermography for in-situ determination of building envelope thermal properties. J. Build. Eng. 2019, 26, 100885. [CrossRef]

25. Norlen, U. Estimating thermal parameters of outdoor test cells. Build. Environ. 1990, 25, 17-24. [CrossRef]

26. Jiménez, M.; Madsen, H.; Andersen, K. Identification of the main thermal characteristics of building components using MATLAB. Build. Environ. 2008, 43, 170-180. [CrossRef]

27. Madsen, H.; Bacher, P.; Bauwens, G.; Deconinck, A.H.; Reynders, G.; Roels, S.; Himpe, E.; Lethe, G. Thermal Performance Characterization Using Time Series Data-IEA EBC Annex 58 Guidelines; DTU Compute-Technical Report-2015; No. 8; Technical University of Denmark (DTU): Lyngby, Denmark, 2015.

28. Teni, M.; Krstić, H.; Kosiński, P. Review and comparison of current experimental approaches for in-situ measurements of building walls thermal transmittance. Energy Build. 2019, 203, 109417. [CrossRef]

29. Jiménez, M.; Porcar, B.; Heras, M. Application of different dynamic analysis approaches to the estimation of the building component U value. Build. Environ. 2009, 44, 361-367. [CrossRef] 
30. Deconinck, A.-H.; Roels, S. A maximum likelihood estimation of the thermal resistance of a cavity wall from on-site measurements. Energy Procedia 2015, 78, 3276-3281. [CrossRef]

31. Fonti, A.; Comodi, G.; Pizzuti, S.; Arteconi, A.; Helsen, L. Low order grey-box models for short-term thermal behavior prediction in buildings. Energy Procedia 2017, 105, 2107-2112. [CrossRef]

32. Bienvenido-Huertas, D.; Rodríguez-Álvaro, R.; Moyano, J.J.; Rico, F.; Marín, D. Determining the U-Value of fa ades using the thermometric method: Potentials and limitations. Energies 2018, 11, 360. [CrossRef]

33. Kim, S.H.; Kim, J.H.; Jeong, H.G.; Song, K.D. Reliability field test of the air-surface temperature ratio method for in situ measurement of U-values. Energies 2018, 11, 803. [CrossRef]

34. Kim, S.H.; Lee, J.H.; Kim, J.H.; Yoo, S.H.; Jeong, H.G. The feasibility of improving the accuracy of in situ measurements in the air-surface temperature ratio method. Energies 2018, 11, 1885. [CrossRef]

35. Evangelisti, L.; Guattari, C.; Asdrubali, F. Comparison between heat-flow meter and Air-Surface Temperature Ratio techniques for assembled panels thermal characterization. Energy Build. 2019, 203, 109441. [CrossRef]

36. Janković, A.; Antunović, B.; Preradović, L. Alternative method for on site evaluation of thermal transmittance. Facta Univ. Ser. Mech. Eng. 2017, 15, 341. [CrossRef]

37. Meng, X.; Gao, Y.; Wang, Y.; Yan, B.; Zhang, W.; Long, E. Feasibility experiment on the simple hot box-heat flow meter method and the optimization based on simulation reproduction. Appl. Therm. Eng. 2015, 83, 48-56. [CrossRef]

38. Scarpa, M.; Ruggeri, P.; Peron, F.; Celebrin, M.; De Bei, M. New Measurement Procedure for U-value Assessment via Heat Flow Meter. Energy Procedia 2017, 113, 174-181. [CrossRef]

39. Meng, X.; Luo, T.; Gao, Y.; Zhang, L.; Shen, Q.; Long, E. A new simple method to measure wall thermal transmittance in situ and its adaptability analysis. Appl. Therm. Eng. 2017, 122, 747-757. [CrossRef]

40. Madding, R. Finding R-values of stud frame constructed houses with IR thermography. Proc. InfraMation 2008, $2008,261-277$. [CrossRef]

41. Fokaides, P.A.; Kalogirou, S.A. Application of infrared thermography for the determination of the overall heat transfer coefficient (U-Value) in building envelopes. Appl. Energy 2011, 88, 4358-4365. [CrossRef]

42. Tejedor, B.; Casals, M.; Gangolells, M.; Roca-Ramon, X. Quantitative internal infrared thermography for determining in-situ thermal behaviour of façades. Energy Build. 2017, 151, 187-197. [CrossRef]

43. Marshall, A.; Francou, J.; Fitton, R.; Swan, W.; Owen, J.; Benjaber, M. Variations in the U-value measurement of a whole dwelling using infrared thermography under controlled conditions. Buildings 2018, 8, 46. [CrossRef]

44. ISO 9869-2. Thermal Insulation-Building Elements-In-Situ Measurement of Thermal Resistance and Thermal Transmittance; ISO: London, UK, 2018.

45. Albatici, R.; Tonelli, A.M. Infrared thermovision technique for the assessment of thermal transmittance value of opaque building elements on site. Energy Build. 2010, 42, 2177-2183. [CrossRef]

46. Albatici, R.; Tonelli, A.M.; Chiogna, M. A comprehensive experimental approach for the validation of quantitative infrared thermography in the evaluation of building thermal transmittance. Appl. Energy 2015, 141, 218-228. [CrossRef]

47. Dall'O', G.; Sarto, L.; Panza, A. Infrared screening of residential buildings for energy audit purposes: Results of a field test. Energies 2013, 6, 3859-3878. [CrossRef]

48. Nardi, I.; Paoletti, D.; Ambrosini, D.; de Rubeis, T.; Sfarra, S. Validation of quantitative IR thermography for estimating the U-value by a hot box apparatus. J. Phys. Conf. Ser. 2015, 655, 012006. [CrossRef]

49. Nardi, I.; Paoletti, D.; Ambrosini, D.; de Rubeis, T.; Sfarra, S. U-value assessment by infrared thermography: A comparison of different calculation methods in a Guarded Hot Box. Energy Build. 2016, 122, 211-221. [CrossRef]

50. Simões, I.; Simões, N.; Tadeu, A.; Riachos, J. Laboratory thermal transmittance assessments of homogeneous building elements using infrared thermography. In Proceedings of the 2014 International Conference on Quantitative InfraRed Thermography, Bordeaux, France, 7-11 July 2014. [CrossRef]

51. Watmuff, J.H.; Charters, W.W.S.; Proctor, D. Solar and wind induced external coefficient-for solar collectors. Coop. Mediterr. Pour Energy Sol. 1977, 2, 56-60.

52. Bienvenido-Huertas, D.; Bermúdez, J.; Moyano, J.; Marín, D. Comparison of quantitative IRT to estimate U-value using different approximations of ECHTC in multi-leaf walls. Energy Build. 2018, 184, 99-113. [CrossRef] 